\title{
The role of mitochondria in statin-induced myopathy
}

\author{
Maria Apostolopoulou ${ }^{*},{ }^{\dagger}$, Alberto Corsini ${ }^{\ddagger, \S}$ and Michael Roden ${ }^{*,+,}$ \\ *Institute for Clinical Diabetology, German Diabetes Center, Leibniz Institute for Diabetes Research, Heinrich Heine University, \\ Düsseldorf, Germany, ${ }^{\dagger}$ German Center for Diabetes Research (DZD e.V.), Düsseldorf, Germany, ${ }^{\ddagger}$ Dipartimento di Scienze \\ Farmacologiche e Biomolecolari (DISFeB), Università degli Studi di Milano, Milan, Italy, ${ }^{\S}$ IRCCS Multimedica, Milan, Italy, \\ "Department of Endocrinology and Diabetology, Medical Faculty, Heinrich Heine University, Düsseldorf, Germany
}

\begin{abstract}
Background Statins inhibit hydroxymethylglutaryl-coenzyme A reductase, decrease plasma low-density lipoprotein cholesterol and reduce cardiovascular morbidity and mortality. They can also exert adverse effects, mostly affecting skeletal muscle, ranging from mild myalgia to rhabdomyolysis.
\end{abstract}

Materials and methods Based on a PubMed search until December 2014, this review summarizes studies on statin effects on muscle mitochondrial morphology and function in the context of myopathy.

Results Possible mechanisms of statin-induced myopathy include lower cholesterol synthesis and production of prenylated proteins, reduced dolichols and increased atrogin-1 expression. Statin-treated patients frequently feature decreased muscle coenzyme Q10 (CoQ10) contents, suggesting that statins might impair mitochondrial function. In cell cultures, statins diminish muscle oxygen consumption, promote mitochondrial permeability transient pore opening and generate apoptotic proteins. Animal models confirm the statin-induced decrease in muscle CoQ10, but reveal no changes in mitochondrial enzyme activities. Human studies yield contradictory results, with decreased CoQ10, elevated lipids, decreased enzyme activities in muscle and impaired maximal oxygen uptake in several but not all studies. Some patients are susceptible to statin-induced myopathy due to variations in genes encoding proteins involved in statin uptake and biotransformation such as the solute carrier organic anion transporter family member 1B1 (SLCO1B1) or cytochrome P450 (CYP2D6, CYP3A4, CYP3A5). Carriers for carnitine palmitoyltransferase II deficiency and McArdle disease also present with higher prevalence of statin-induced myopathy.

Conclusions Despite the widespread use of statins, the pathogenesis of statin-induced myopathy remains unclear, requiring prospective randomized controlled trials with intensive phenotyping also for identifying strategies for its risk assessment, prevention and treatment.

Keywords Mitochondria, myopathy, skeletal muscle, statins, ubiquinone.

Eur J Clin Invest 2015; 45(7):745-754

\section{Introduction}

Statins are highly effective drugs on lowering plasma low-density lipoprotein (LDL) cholesterol by competitively inhibiting hydroxymethylglutaryl-coenzyme A (HMG-CoA) reductase, an enzyme catalysing the rate-limiting step in the mevalonate pathway. Their action takes place mainly in the liver, where LDL receptors are increased due to the decreased hepatocyte cholesterol. Other effects include the modest increase in high-density lipoprotein (HDL) cholesterol and minor decrease of plasma triglycerides [1]. Next to these lipid-lowering effects, statins increase stability of the atherosclerotic plaques, decrease inflammation and oxidative stress and improve endothelial function [2]. Taken together these different 'pleiotropic' actions are likely responsible for the lower risk of cardiovascular morbidity and mortality of statin-treated patients even in the primary prevention setting [3].

Although statins are generally considered well-tolerated, their wide use has shed light on adverse effects that can result to intolerance and discontinuation of the treatment. Aside from elevation of liver enzymes and risk of incident diabetes, the most common side effect is myotoxicity. Mild muscle symptoms are reported in 10-20\% of the patients treated with statins in large community based studies [4-6]. The term 'myopathy' defines a wide range of muscular symptoms, whereas 'myositis' demands the increase of creatine kinase (CK) levels, with 'rhabdomyolysis' being the most life-threatening form with excessive $\mathrm{CK}$ elevation as a result of massive muscle destruction and myoglobinuria. However, the incidence of rhabdomyolysis during statin treatment is very low $(0 \cdot 003-0 \cdot 1 \%)$ [5-7]. The wide range of reported 
data on the incidence may be due to the lack of standardized clinical diagnostic criteria for statin-related adverse events. Of note, CK elevation is not generally considered to be required for treatment discontinuation, when patients claim muscle pain [8].

There are several mechanisms that are proposed to be involved in the statin-induced myopathy. Statin-induced inhibition of HMG-CoA reductase also results in the lowering of several other intermediates of the pathway, such as dolichols, prenylated proteins and electron transport chain proteins, heme A and ubiquinone (coenzyme Q10, CoQ10), which shuttles between complex I and II (CI and CII) of the mitochondrial electron transport chain (ETC.). The frequent observation of decreased concentrations of CoQ10 not only in the circulation, but also in skeletal muscle of statin-treated humans and rodents [9], has led to the suggestion that statins may interfere with mitochondrial function, which could in turn impair muscle function and damage muscle morphology.

The aim of this review was to summarize studies in cell lines, animal models and humans on the impact of statins on the key features of muscle mitochondrial morphology and function both in vivo and in vitro. Furthermore, this review includes studies on possible mechanistic interactions between muscle mitochondria and statin-induced myopathy. Finally, risk factors for muscle statin intolerance are also briefly discussed. There have been previous reviews addressing related topics [4,6,9-11].

To this end, we identified publications in English language referring to statin treatment and muscle adverse events via a PubMed search until December 2014. Publications specifically addressing the relationship between statin treatment and mitochondrial function impairment were analysed in detail. The PubMed search was performed using the following combinations of the terms: 'statin AND mitochondria AND myopathy AND human, animal, cell cultures', respectively. We identified 22 original papers on humans, 19 publications on animal models, 10 publications in cell cultures and 13 reviews. We included only these studies, which reported data on ubiquinone content, mitochondrial morphology and mitochondrial complex activity. We excluded all studies that examined statin effects on mitochondria in tissues other than skeletal muscle or focused on muscle fibre alteration rather than reporting data on mitochondrial function. We finally included 12 original papers on humans, five on animal models, five on cell cultures and eight reviews meeting the criteria. Additional publications were identified from the reference list of the retrieved publications or from authors' knowledge.

\section{Possible mechanisms of statin-induced myopathy not directly linked to mitochondria}

Cholesterol is a basic component of the cell membrane, contributing to its stability. Its reduction by statins results in changes in membrane fluidity and modification of muscle membrane susceptibility. Membrane alterations can modulate the function of sodium, potassium and chloride channels, subsequently damaging myocytes and causing myopathy [12,13] (Fig. 1).

Statins also inhibit farnesyl pyrophosphate and geranylgeranyl pyrophosphate, intermediates of the mevalonate pathway, which are involved in the post-translational modification of proteins such as small GTPases and lamins. GTPases and lamins play an important role in cell maintenance and chromatin organization (Fig. 1). Dysprenylation of small GTPases has been shown to result in muscle fibre degeneration and apoptosis, whereas lamin dysprenylation may result in fragile nuclear membranes and induce muscle cell apoptosis [14,15]. Dolichols, other intermediates of the mevalonate pathway, promote protein $\mathrm{N}$-glycosylation. Inhibition of their production by statins impairs the expression of receptors and the production of structural proteins, which may also lead to myopathy [12,15] (Fig. 1). Treatment of pre-adipocytes with $10 \mathrm{nmol} / \mathrm{L}$ cerivastatin resulted in impaired production of structural proteins and receptors with accumulation of proreceptors and apoptosis after prolonged exposure [16], suggesting disruption of N-glycosylation, as the mechanism underlying cell damage.

Statins have been also associated with increased expression of atrogin-1, a gene linked to muscle atrophy [17]. Atrogin-1 expression occurs early during the development of muscle atrophy, and its increase precedes the loss of muscle mass. Of note, patients with statin-associated myopathy exhibit increased mRNA levels of atrogin-1 in biopsies of quadriceps muscle [18].

\section{The role of CoQ10 during statin treatment}

The impact of mitochondria on statin-induced myopathy originally derived from the finding of lower CoQ10 in the circulation and skeletal muscle of statin-treated patients and higher lactate/pyruvate ratios, as indicator of abnormal mitochondrial function $[19,20]$. CoQ10 is a basic electron transporter of the respiratory chain of the mitochondria and the end product of the mevalonate pathway.

Several studies reported a decrease in plasma CoQ10 levels in statin-induced myopathy, as recently reviewed [9]. However, the reported decreases in CoQ10 levels may be due to the simultaneous reduction of LDL cholesterol, which is the main transporter of CoQ10 in the circulation [9]. There also seems to be a statin type-specific influence on CoQ10 levels, as rosuvastatin but not atorvastatin was found to preserve CoQ10 levels in patients with coronary artery disease, when each drug was combined with aerobic exercise. However, this study did not include a control group treated with the statins or exercise only [21]. Lower plasma CoQ10 levels do not generally reflect lower muscle CoQ10 levels, as demonstrated by contradictory results of skeletal muscle biopsies [22-24]. 


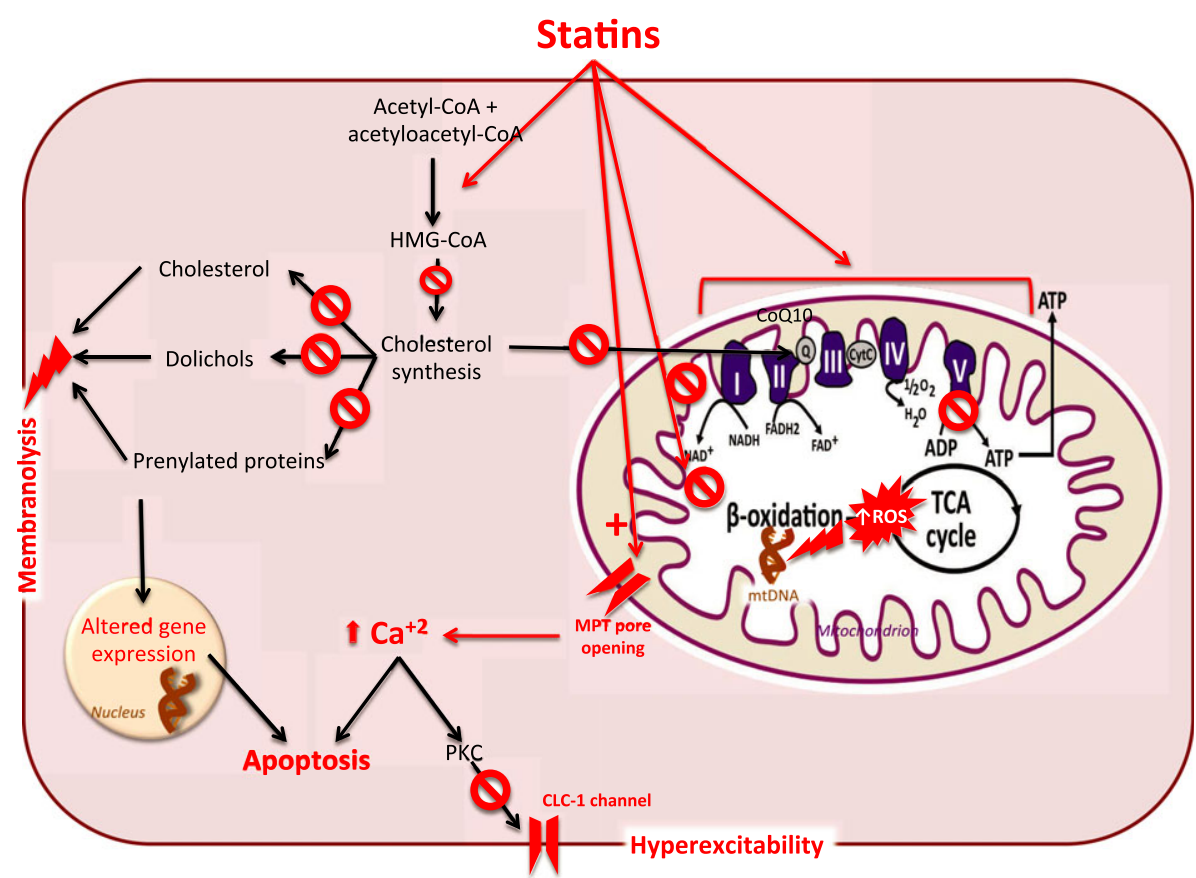

Figure 1 Possible mechanisms of statin-induced myopathy. Statin-treated patients feature lower cholesterol synthesis and production of prenylated proteins and dolichols, which can lead to membranolysis and/or apoptosis in skeletal muscle. Impaired mitochondrial function and elevated ROS can result from reduced CoQ10 content, as well as inhibition of the electron transport chain and of beta oxidation. Finally, increased intracellular calcium levels due to accelerated mitochondrial MPT pore opening can also cause apoptosis or via PKC inhibit CLC-1 channels with consecutive hyperexcitability of the cytoplasmic membrane. HMG-CoA: hydroxymethylglutaryl-coenzyme A, PKC: protein kinase C, CLC-1: chloride channel protein-1, CoQ10: coenzyme Q10, cyt c: cytochrome c, ROS: reactive oxygen species, TCA cycle: tricarboxylic acid cycle, MPT pore: mitochondrial permeability transition pore.

Thus, it is not surprising that the supplementation with CoQ10 to prevent or treat statin-induced myopathy revealed contradictory results. Some studies showed that CoQ10 administration can increase CoQ10 blood levels in statin-treated patients [25-28]. Two studies on the frequency of myopathic symptoms reported improvement of statin-related muscle complaints upon CoQ10 (240 mg/day) coadministration in patients with gastric adenocarcinoma treated with high-dose lovastatin (35-45 mg/kg/day) [29,30]. However, the absence of control groups and data from muscle biopsies prevents us from drawing conclusions on the benefit of CoQ10 administration in these specific patient cohorts. Most reviews, finally, do not support any benefit from CoQ10 supplementation when compared to placebo in patients on usual statin doses [9,10,31-33]. One recent study examined the effect of $600 \mathrm{mg} / \mathrm{d}$ CoQ10 supplementation on myopathic symptoms of patients assigned to $20 \mathrm{mg} / \mathrm{d}$ simvastatin. Myopathy appeared irrespective of the assignment to CoQ10 treatment [34]. Of note, current guidelines or position statements do not recommend CoQ10 supplementation to increase adherence to statin treatment $[8,35]$.

\section{Possible mechanisms of statin-induced myopathy directly linked to mitochondria}

Next to the lowering CoQ10 levels, statins were suggested to exert direct effects on the ETC., as pravastatin accelerated the age-dependent impairment of CI function in rat muscle cells [36].

Furthermore, impaired calcium signalling could also contribute to statin-induced myopathy. Statins are proposed to induce mitochondrial depolarization and calcium release resulting in cytoplasmic calcium waves with subsequent calcium release by the sarcoplasmic reticulum as a possible mechanism of caspase activation and induction of apoptosis [9,15,37-39] (Fig. 1). The cytosolic calcium increase may also raise $\mathrm{Ca}^{2+}$ - and phospholipid-dependent protein kinase $\mathrm{C}$ (PKC) activity, which promotes closing of the chloride channel 1, CLC1 , resulting in membrane hyperexcitability, as shown in muscles of rats chronically treated with fluvastatin or atorvastatin [40].

Moreover, there is evidence of increased lipid peroxidation and oxidative stress after statin treatment. Exposing primary 
human muscle cells to simvastatin for $48 \mathrm{~h}$ resulted in impaired ADP-stimulated mitochondrial respiration, increased reactive oxygen species (ROS) production and activation of apoptosis [41] (Fig. 1). In contrast, statins may exert opposite effects on cardiac muscle mitochondria by enhancing PGC-1 $\alpha$ expression and lowering ROS production [42], whereas oxidative capacity appeared to be decreased in skeletal muscle of statin-treated patients.

\section{Studies on the effects of statins on muscle mitochondria and energy metabolism}

The effects of statins on muscle energy metabolism have been studied in cell cultures (Table 1), animal models (Table 2) as well as in humans (Table 3). The most interesting features tested in cell cultures were mitochondrial membrane potential, maximal oxygen uptake and ATP levels. In animal models and human studies, muscle CoQ10 levels have been also measured in addition to assessing mitochondrial enzyme activities and ROS production.

\section{Studies in cell cultures}

Few studies have examined the effect of statin application on cell cultures, mainly providing indications for a mitochondrial mechanism involved in muscle cell apoptosis (Table 1).

Exposure of rat L6 cell lines to cerivastatin, fluvastatin, atorvastatin, simvastatin but not pravastatin decreases glutamatedriven state 3 respiration and respiratory control, and lowered beta oxidation and DNA fragmentation by $88-96 \%$ indicating that lipophilic statins mainly impair mitochondrial function, with pravastatin being less toxic [43]. In C2C12 myotubes but not HepG12 cells, simvastatin decreased mitochondrial membrane potential and oxygen consumption [44]. This was attributed to impaired insulin growth factor-1/protein kinase B (Igf-1/Akt) signalling leading to abnormal mitochondrial function, whereas some liver cell lines may be protected by intact Igf-1/ Akt signalling.

In differentiated primary human skeletal muscle cells, simvastatin decreased maximal oxygen consumption, promoted mitochondrial PTP opening and increased levels of Bax and $\mathrm{Bcl}-2$ proteins, in line with impaired complex I respiration [41]. Another study in human rhabdomyosarcoma cells treated with simvastatin showed a decrease in ATP levels, which was reversed by the application of ubiquinone [45]. These data provide evidence for impaired mitochondrial function, which can be reversed by CoQ10 at least in cell cultures.

\section{Studies in animal models}

Although studies in several animal models have confirmed muscle injury upon statin treatment, they did not consistently support the concept of compromised muscle mitochondrial function (Table 2).

Treating male rabbits with simvastatin and pravastatin resulted in decreased muscle ubiquinone content, but did not affect mitochondrial enzyme activities [46]. Interestingly, cerivastatin but not pravastatin treatment of female rats for 15 days raised serum CK levels and induced muscle necrosis along with swollen mitochondria, while mitochondrial enzyme activities were unchanged [47]. Nevertheless, another study on treating

Table 1 Parameters of mitochondrial function studied in cell cultures

\begin{tabular}{|c|c|c|c|}
\hline Reference & Statin (name, dose) & Cell type & Findings \\
\hline Sirvent et al. [39] & $\mathrm{S}$ & Rat skinned skeletal muscle & Inhibition of $\mathrm{Cl}$ \\
\hline Kaufmann et al. [43] & C, F, A, S, P $100 \mathrm{mmol} / \mathrm{L}$ & L6 cells & $\begin{array}{l}\text { S,F,A: } 46-65 \% \downarrow \text { Mitochondrial membrane } \\
\text { potential, C,S,F,A: } \downarrow \text { Respiratory control } \\
\text { ratio, } \downarrow \text { Glutamate-driven state } 3 \text { respiration, } \\
88-96 \% \downarrow \beta \text { oxidation, DNA fragmentation } \\
\text { mitochondrial swelling }\end{array}$ \\
\hline Mullen et al. [44] & $\mathrm{S}, 20 \mu \mathrm{mol} / \mathrm{L}$ for $72 \mathrm{~h}$ & $\begin{array}{l}\text { Primary mouse skeletal muscle } \\
\text { myocytes, C2C12 myotubes } \\
\text { and liver HepG2 cells }\end{array}$ & $\begin{array}{l}\downarrow \text { Mitochondrial membrane potential, } \downarrow \mathrm{O}_{2} \\
\text { consumption and Akt PY in C2C12 myotubes } \\
\text { but not in HepG } 2 \text { cells }\end{array}$ \\
\hline Kwak et al. [41] & $\begin{array}{l}\mathrm{S}, 5.0 \mu \mathrm{mol} / \mathrm{L} \\
\mathrm{S}, 5.0 \mu \mathrm{mol} / \mathrm{L}+\mathrm{mevalonate} \\
50 \mu \mathrm{mol} / \mathrm{L} \text { for } 48 \mathrm{~h}\end{array}$ & $\begin{array}{l}\text { Differentiated primary human } \\
\text { skeletal muscle cells }\end{array}$ & $\begin{array}{l}\text { S: } 32-27 \% \downarrow \text { Maximal ADP-stimulated } \mathrm{O}_{2} \\
\text { consumption } \\
\uparrow \text { Protein levels of Bax and Bcl-2 }\end{array}$ \\
\hline Vaughan et al. [45] & $\begin{array}{l}\mathrm{S}, 5,10 \mu \mathrm{mol} / \mathrm{L} \\
\mathrm{S}, 5 \mu \mathrm{mol} / \mathrm{L}+\text { ubiquinone } \\
0.5,1.0 \mu \mathrm{mol} / \mathrm{L} \text { for } 24 \mathrm{~h} \text { or } 48 \mathrm{~h}\end{array}$ & Rhabdomyosarcoma cells & $\begin{array}{l}\text { S: } \downarrow \text { mito staining, } \downarrow \text { ATP } \\
\text { Ubiquinone reverses suppression } \\
\text { at } 1.0 \mu \mathrm{mol} / \mathrm{L}\end{array}$ \\
\hline
\end{tabular}

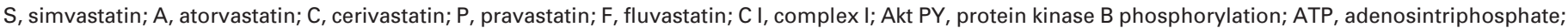
ADP, adenosindiphosphate; Bcl-2 protein, B-cell lymphoma-2 protein; Bax, Bcl-2-associated protein. 
Table 2 Parameters of mitochondrial function studied in animal models

\begin{tabular}{|c|c|c|c|c|}
\hline Reference & Statin (name, dose) & $\begin{array}{l}\text { Duration } \\
\text { in days }\end{array}$ & Animal model & Findings \\
\hline Nakahara et al. [46] & $\begin{array}{l}\mathrm{S}, 100 \mathrm{mg} / \mathrm{kg} / \mathrm{day} \\
\mathrm{P}, 100 \mathrm{mg} / \mathrm{kg} / \mathrm{day} \\
\mathrm{P}, 200 \mathrm{mg} / \mathrm{kg} / \mathrm{day} \\
+300 \mathrm{mg} / \mathrm{kg} / \mathrm{day}\end{array}$ & $\begin{array}{l}28 \\
28 \\
21 / 21\end{array}$ & $\begin{array}{l}\text { Male New Zealand } \\
\text { white rabbits }\end{array}$ & $\begin{array}{l}\text { S: } \uparrow \text { CK, muscle necrosis, } \downarrow \text { Ubiquinone } \\
\text { content }=\text { Mitochondrial enzyme activities } \\
\text { in all groups }\end{array}$ \\
\hline Schaefer et al. [47] & $\mathrm{C}, 0.1,0.5,1.0 \mathrm{mg} / \mathrm{kg} / \mathrm{day}$ & 15 & $\begin{array}{l}\text { Female Sprague-Dawley } \\
\text { Crl: CD(SD)IGSBR rats }\end{array}$ & $\begin{array}{l}\uparrow \mathrm{CK} \text {, muscle necrosis, inflammation } \\
\text { at higher dose } \\
\text { Altered mitochondria in fibres with } \\
\text { degeneration }\end{array}$ \\
\hline Obayash et al. [48] & $\mathrm{C}, 2 \mathrm{mg} / \mathrm{kg} / \mathrm{day}$ & 10 & F344 rats & $\begin{array}{l}\text { Necrosis of soleus muscle fibres, prior to } \\
\text { manifestation swollen mitochondria }\end{array}$ \\
\hline Bouitbir et al. [42] & A, $10 \mathrm{mg} / \mathrm{kg} / \mathrm{day}$ & 14 & Male Wistar rats & $\uparrow R O S$ in skeletal muscle, $\downarrow$ PGC- $1 \alpha$ expression \\
\hline Ranji et al. [50] & - & - & $\begin{array}{l}\text { C. elegans hmgr-1 mutant } \\
\text { (lacks HMG-CoA reductase) }\end{array}$ & $\begin{array}{l}\text { Defective mitochondrial morphology, } \\
\text { protein prenylation } \\
\text { Reversible with mevalonate within } 24 \mathrm{~h}\end{array}$ \\
\hline
\end{tabular}

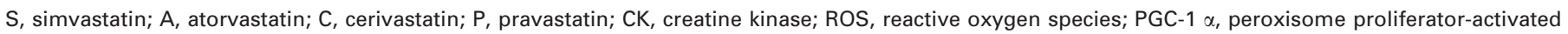
receptor gamma coactivator $1-\alpha$.

rats with cerivastatin documented type I fibre muscle injury and swollen mitochondria prior to the onset of muscle necrosis suggesting early involvement of mitochondria in the development of statin-induced myopathy [48]. Moreover, 2-weeks treatment with atorvastatin increased ROS production and decreased PGC-1 $\alpha$ expression in rat skeletal muscle cells, providing evidence for decreased mitochondrial biogenesis and augmented oxidative stress [42]. Of note, these authors also found that endurance training of the rats improved mitochondrial respiration and oxidative capacity and protected the skeletal muscle mitochondria against statin exposure [49]. Also, mevalonate recovers abnormalities in skeletal muscle morphology rapidly within $24 \mathrm{~h}$ in a C. elegans hmgr-1 mutant, which lacks HMG-CoA reductase and can therefore serve as a model of statin treatment [50].

\section{Studies in humans}

Several studies examined the effect of statins on skeletal muscle of patients treated with different statins at various doses. Some studies specifically examined the effect of statins on mitochondrial function in muscle biopsies in statin-treated patients with or without signs of myopathy as well as in control persons [22-24,42,51-57] (Table 3).

Lactate/pyruvate ratios were found to be significantly higher in patients treated with statins compared to controls, a finding that provided the first evidence that statin therapy may be associated with abnormal mitochondrial metabolism [19]. In three patients with symptoms of myopathy likely related to statin use, muscle biopsies showed abnormally elevated lipid stores, ragged red fibres and fibres with decreased staining for cytochrome c activity, a biomarker of mitochondrial activity [58]. These abnormalities disappeared after withdrawal of the statin. The retrospective design accounts for the lack of biopsies at baseline and the absence of a control group of patients with myopathy unrelated to statin use and represents a shortcoming of this study. Comparing treatment of $80 \mathrm{mg} /$ day simvastatin with that of $40 \mathrm{mg} /$ day atorvastatin for 8 weeks showed a 30\% decrease of muscle CoQ10 in the simvastatin group along with decreased ETC. enzyme activities and apparently 39\% lower plasma CoQ10 levels in the atorvastatin group [22]. Three other studies on simvastatin, atorvastatin or placebo treatment found lower muscle CoQ10 levels in the simvastatin-treated groups $[23,24,59]$. Hypercholesterolaemic patients on simvastatin treatment (10-40 mg/day) had lower muscle content of ubiquinone and CIV activity along with decreased maximal ex vivo oxidative capacity [23]. Of note, mitochondrial content was comparable in the simvastatin-treated group and control groups. Strengths of this study are its well-matched control group and the use of established methods for assessment of mitochondrial CoQ10 content and mitochondrial function. In 48 patients assigned to simvastatin $80 \mathrm{mg} /$ day, atorvastatin $40 \mathrm{mg}$ / day or placebo for 8 weeks, muscle CoQ10 decreased in the simvastatin group only and mtDNA/nDNA ratio fell by $47 \%$ in both statin-treated groups suggesting lower mitochondrial density [24]. A small study in patients presenting with myopathic symptoms during statin treatment revealed signs of abnormal mitochondrial function, such as subsarcolemmal 
Table 3 Parameters of mitochondrial function studied in humans

\begin{tabular}{|c|c|c|c|c|c|}
\hline Reference & Cohort (n, diagnosis) & $\begin{array}{l}\text { Statin } \\
\text { (name, dose) }\end{array}$ & $\begin{array}{l}\text { Duration in } \\
\text { months }\end{array}$ & $\begin{array}{l}\text { Muscle } \\
\text { CoQ10 }\end{array}$ & Other findings \\
\hline Paiva et al. [22] & 48 hypercholesterolaemia & $\begin{array}{l}\mathrm{S}, 80 \mathrm{mg} / \mathrm{day} \\
\mathrm{A}, 40 \mathrm{mg} / \mathrm{day}\end{array}$ & 2 & $30 \%$ in $\mathrm{S}$ & $\begin{array}{l}\text { S: } \downarrow \text { Cl, II, III, IV, CS 30\% } \downarrow \text { CoO10 } \\
\text { A: } 39 \% \downarrow \text { CoQ } 10\end{array}$ \\
\hline Lamperti et al. [51] & $\begin{array}{l}18 \text { hypercholesterolaemia } \\
\text { with myopathic symptoms }\end{array}$ & $\begin{array}{l}\mathrm{S}, \mathrm{C}, \mathrm{A}, \\
\mathrm{R} 5 / 10 / 20 \mathrm{mg} / \mathrm{day}\end{array}$ & n. r. & in 10 pts & $\begin{array}{l}\text { Cytochrome c oxidase-negative } \\
\text { ragged red fibres in } 2 \text { pts }\end{array}$ \\
\hline Guis et al. [52] & $\begin{array}{l}11 \text { hypercholesterolaemia } \\
\text { with statin-induced CK } \\
\text { elevation } 8 \text { healthy }\end{array}$ & $\begin{array}{l}\text { A, } 10 \mathrm{mg} / \mathrm{day} \\
\mathrm{S}, 5-20 \mathrm{mg} / \mathrm{day} \\
\text { C, } 10 \mathrm{mg} / \mathrm{day} \\
\text { P, } 5-20 \mathrm{mg} / \mathrm{day} \\
\text { F, } 10 \mathrm{mg} / \mathrm{day}\end{array}$ & n. r. & - & $\begin{array}{l}\text { = cytochrome oxidase activity, } \\
\text { PCr recovery } \\
\text { F,S,A,P,S: Abnormal in vitro } \\
\text { contracture tests in } 7 \text { pts }\end{array}$ \\
\hline Schick et al. [24], & 48 hypercholesterolaemia & $\begin{array}{l}\mathrm{S}, 80 \mathrm{mg} / \mathrm{day} \\
\text { A, } 40 \mathrm{mg} / \mathrm{day} \\
\text { Placebo }\end{array}$ & 2 & in $\mathrm{S}$ & $\begin{array}{l}\text { S: } 47 \% \\
\downarrow \text { mtDNA/nDNA }\end{array}$ \\
\hline Traustadottir et al. [53] & $\begin{array}{l}12 \text { healthy men and } \\
\text { women, } L D L>130 \mathrm{mg} / \mathrm{dl}\end{array}$ & $\mathrm{S}, 80 \mathrm{mg} / \mathrm{day}$ & 3 & - & $=\mathrm{VO}_{2} \max , \mathrm{RER}, \mathrm{O}_{2}$ uptake kinetics \\
\hline Wu et al. [54] & 10 hypercholesterolaemia & $\mathrm{S}, 20 \mathrm{mg} / \mathrm{day}$ & 1 & - & $\downarrow P C r$ recovery \\
\hline Bouitbir et al. [42] & 5 statin-induced myopathy & $\begin{array}{l}\text { A, } 10 \mathrm{mg} / \mathrm{day} \\
\mathrm{R}, 10 \mathrm{mg} / \mathrm{day} \\
\mathrm{S}, 10-20 \mathrm{mg} / \text { day }\end{array}$ & $6-60$ & - & $\mathrm{A}, \mathrm{R}, \mathrm{S}: \uparrow \mathrm{ROS}, \downarrow \mathrm{PGC}-1 \alpha, \downarrow \mathrm{PGC}-1 \beta$ \\
\hline Mikus et al. [55] & $\begin{array}{l}37 \text { with }>2 \text { metabolic } \\
\text { syndrome risk factors }\end{array}$ & $\mathrm{S}, 40 \mathrm{mg} / \mathrm{day}$ & 3 & - & $\begin{array}{l}\mathrm{S}: 4.5 \% \downarrow \mathrm{CS} \\
=\mathrm{VO}_{2} \mathrm{max} / \mathrm{kg}\end{array}$ \\
\hline Stringer et al. [56] & 23 statin-induced myopathy & $\begin{array}{l}\mathrm{S}>80 \mathrm{mg} / \mathrm{day} \\
<80 \mathrm{mg} / \mathrm{day} \\
\mathrm{A}>40 \mathrm{mg} / \text { day }\end{array}$ & n. r. & & S: $\downarrow \mathrm{mtDNA}, \downarrow \mathrm{mtDNA} / \mathrm{nDNA}$ \\
\hline Larsen et al. [23] & 10 hypercholesterolaemia & $\mathrm{S}, 10-40 \mathrm{mg} / \mathrm{day}$ & 60 & in $\mathrm{S}$ & $\begin{array}{l}\downarrow \mathrm{C}, \mathrm{IV} \\
=\text { mito content } \\
\text { OXPHOS }\end{array}$ \\
\hline Parker et al. [57] & 420 healthy & A, $80 \mathrm{mg} / \mathrm{day}$ & 6 & - & $\begin{array}{l}\uparrow \text { muscle complaints } \\
=\text { muscle strength } \\
\mathrm{VO}_{2} \max \end{array}$ \\
\hline
\end{tabular}

S, simvastatin; A, atorvastatin; C, cerivastatin; R, rosuvastatin; P, pravastatin; F, fluvastatin; CoQ10, coenzyme Q10; PCr recovery, phosphocreatine recovery; pts, patients; CK, creatine kinase; mtDNA, mitochondrial DNA; nDNA, nuclear DNA; LDL, low-density lipoprotein; VO2max, maximal oxygen uptake; RER, respiratory exchange ratio; ROS, reactive oxygen species; PGC-1 $\alpha, \beta$, peroxisome proliferator-activated receptor gamma coactivator $1-\alpha, \beta$; n.r, not reported; OXPHOS, oxidative phosphorylation; ATP, adenosintriphosphate.

accumulation of mitochondria, lipid increase and Cox negative fibres [59].

However, not all studies come to the conclusion that muscle mitochondrial function is impaired due to statin treatment. Six months of simvastatin treatment $(20 \mathrm{mg} /$ day) neither resulted in changes from baseline in CoQ10 levels nor in high-energy phosphate concentrations in skeletal muscle biopsies, compared to the untreated control persons [60]. While this was explained by the rather low dose of simvastatin used, another albeit retrospective analysis of muscle biopsies obtained from 23 patients with statin-related myopathy compared to those of patients with statin-unrelated myopathy found no direct association with statins [56]. Nevertheless, muscle mtDNA was lower in patients with statin-induced myopathy, but there was no difference between both groups in mtDNA deletion score or oxidative mtDNA damage, suggesting that the observed mtDNA depletion did not lead to qualitative damage of muscle mitochondria. A limitation of this study is the absence of data on baseline mtDNA content.

Another study assessed mitochondrial biogenesis and oxidative stress from ROS production and PGC- $1 \alpha$ and PGC-1 $\beta$ gene expression in skeletal and cardiac muscle cells of patients 
treated with statins. Here, the five patients with statin-induced myopathy exhibited increased ROS production and decreased PGC-1 $\alpha$ and PGC-1 $\beta$ gene expression [42]. This study provides evidence for a different mechanism of statin action on skeletal and cardiac muscle mitochondria. In cardiac muscle cells, ROSinduced PGC-1 family expression was stimulated, whereas in skeletal muscle cells, which lack sufficient antioxidant mechanisms, the oxidative damage prevailed. Using animal models and cell cultures allowed for comprehensive investigation of the possible mechanisms of statin action.

Only few studies employed non-invasive in vivo techniques to quantify submaximal oxidative capacity, such as spiroergometry and ${ }^{31} \mathrm{P}$ magnetic resonance spectroscopy. Two spiroergometry studies found no changes of maximal oxygen uptake $\left(\mathrm{VO}_{2} \mathrm{max}\right)$ and oxygen uptake kinetics after 12 weeks of simvastatin treatment ( $80 \mathrm{mg} /$ day) in 10 patients [53] or after 6 months of atorvastatin ( $80 \mathrm{mg} /$ day) when compared with placebo [57]. Of note, CK levels and muscle symptoms were higher in the atorvastatin group despite unchanged parameters of exercise performance after 6 weeks of atorvastatin treatment. However, these studies lack efficient control of exercise monitoring during the intervention period, as well as data from intramuscular CoQ10 levels, because no muscle biopsies were performed. Interestingly, an exercise training study provided some evidence for reduced physical performance after statin use [55]. This study randomized patients, who had features of the metabolic syndrome, to aerobic training with or without simvastatin (40 mg/day) for 12 weeks. $\mathrm{VO}_{2}$ max increased by $10 \%$ in the statin-free group, but only by $1.5 \%$ in the statintreated group, which also showed a small $4.5 \%$ decrease in muscle citrate synthase enzyme activity, a marker of mitochondrial density and/or activity. A limitation of this study resides in the lack of placebo administration in the control group performing exercise only. Nevertheless, statins may blunt the beneficial effect of exercising on cardiorespiratory and muscular fitness via interfering with mitochondria.

While spiroergometry yields a rather indirect measure with several limitations, measurement of the half-time of muscle phosphocreatine $(\mathrm{PCr})$ recovery upon exercise-induced $\mathrm{PCr}$ depletion using ${ }^{31} \mathrm{P}$ magnetic resonance spectroscopy provides a direct measure of submaximal mitochondrial oxidative capacity [61]. Using this method, simvastatin (20 mg/day) treatment for 4 weeks led to prolonged, that is impaired $\mathrm{PCr}$ recovery time in 10 hypercholesterolaemic patients [54]. In this study, four of five patients with prior statin use experienced myalgia suggests a bias in the patient selection, as the symptom frequency is not representative for the general population treated with statins. Another study reported normal PCr recovery times in statin-treated patients and suggested that myoskeletal symptoms may become evident only in the presence of altered calcium homoeostasis [52]. However, the small sample size with only 11 patients treated with various doses of five statins for an unreported period of time makes it difficult to compare the different statins and doses.

\section{Risk factors for statin-induced myopathy}

It is clinically relevant to detect factors that increase the risk of statin-induced myopathy in order to identify persons at risk and/or to adjust or modify the treatment of such patients. Increasing age [62], female gender [63], renal insufficiency, subclinical hypothyroidism and polypharmacy have been related to increased risk of statin-induced myopathy $[10,11,64]$. Other risk factors include high levels of physical activity, alcohol and drug abuse, HIV infection, severe trauma and surgery with increased metabolic demands [10].

In addition, genetic factors may also play a role by increasing the susceptibility of some patients to adverse effects of statins. The SLCO1B1 gene encodes a protein responsible for the hepatic uptake of statins, and polymorphisms in this gene are tightly associated with statin-induced myopathy $[65,66]$. Also, polymorphisms in genes of the cytochrome P450 system (CYP2D6, CYP3A4, CYP3A5) and efflux transporters (ABCB1, ABCG2) have been studied in this context [66]. CYP2D6 gene polymorphisms have been associated with increased susceptibility to atorvastatin-induced muscle side effects [67]. Several mutations in the PYGM gene (McArdle's disease), CPT-II deficiency and AMPD1 gene as well as the ryanodine receptor 1 (RYR1) gene have also been associated with increased risk and severity of statin-associated myopathy [68,69].

Specifically, patients with inherited mitochondrial diseases, such as mitochondrial myopathy, encephalopathy, lactic acidosis and stroke-like episodes (MELAS syndrome) [10], myoadenylate deaminase (MADA) deficiency and variations of the CoQ10 gene appear to have higher susceptibility for statinassociated myopathy [70]. Polymorphisms of the CoQ2 gene, which is important for the CoQ10 synthesis, are associated with primary CoQ10 deficiency and severe mitochondrial myopathy [65]. But even mild variants of this gene were associated to increased susceptibility of the carriers for statin-induced myopathy. On the other hand, statin treatment per se can induce MELAS-like syndrome in vulnerable individuals [71]. Of note, a case report of a woman with MELAS syndrome due to A3243G mutation showed marked reduction not only of insulin secretion but also of muscle ATP synthesis at baseline and during insulin stimulation [72]. Another case report of a teenager with the A3243G mutation, which accounts for more than $80 \%$ of the mutations found in MELAS syndrome patients, showed that statin treatment led to increased CK levels and myopathic symptoms despite normal CoQ10 levels and respiratory chain enzyme activities [73]. This suggests that direct effects of statins on mitochondria do not necessarily explain 
increased susceptibility in all patients with mitochondrial diseases.

Statin dose and properties are important determinants of myotoxicity, with higher lipophilicity and interaction with drug metabolizing pathways such as CYP increasing risk for adverse muscle $[11,74]$. A recent study also showed that individuals with $25-\mathrm{OH}$ vitamin $\mathrm{D} 3$ below $15 \mathrm{mg} / \mathrm{mL}$ on statin had a higher incidence of muscle adverse effects compared to those without statin, providing some evidence that vitamin $\mathrm{D}$ deficiency also represents another risk condition for muscle adverse effects in patients treated with statins [75].

Of note, patients with diabetes mellitus and/or obesity seem to be at greater risk of statin-related adverse events. Among patients with diabetes, statin use was associated with $29 \%$ higher risk for statin-associated myopathy [76]. In the SEARCH trial using treatment with $80 \mathrm{mg} /$ day simvastatin, diabetes at baseline was associated with 'definite or incipient myopathy' with an overall relative risk of 1.7 and a relative risk of 2.3 after 1 year [77]. Overall statin-associated complications were also more frequent in patients with body mass index (BMI) above $29 \mathrm{~kg} / \mathrm{m}^{2}$ [78]. Given the increasing prevalence of diabetes and obesity, studies on statin-related adverse events should specifically address obese patients with type 2 diabetes in future studies.

\section{Conclusions}

This review focused on the effect of statins on mitochondrial function in cell cultures, animal models and humans. It remains unclear whether or not impaired mitochondrial function is a consistent result of statin treatment and involved in statinassociated myopathy. Most available studies suffer from certain limitations, such as including small cohort size, inconsistencies in the diagnostics of statin-associated myopathy and application methods, which do not allow for exact assessment of mitochondrial function. Larger prospective randomized controlled trials on a multinational level with specific phenotyping are therefore needed for the better understanding of the pathogenesis of statin-induced myopathy and the role of muscle mitochondrial function. Intensified and standardized phenotyping including detailed assessment of mitochondrial function as well as genetic screening, mRNA and proteomic fingerprinting are likely the most promising strategies for the identification of persons susceptible to adverse muscle effects of statins. These measures would support guidelines regarding effective statin use and thereby promote prevention, reversal and treatment of unwanted effects of statins.

\section{Acknowledgements}

The work of MR is supported by the Ministry of Science and Research of the State of North Rhine-Westphalia (MIWF NRW) and the German Federal Ministry of Health (BMG). The research of MR is supported in part by a grant of the Federal Ministry for Research (BMBF) to the German Center for Diabetes Research (DZD e.V.) and by the Helmholtz Alliance with Universities (Imaging and Curing Environmental Metabolic Diseases, ICEMED). No potential conflict of interests relevant to this article were reported.

\section{Address}

Institute for Clinical Diabetology, German Diabetes Center, Leibniz Institute for Diabetes Research, Heinrich Heine University, c/o Auf'm Hennekamp 65, 40225 Düsseldorf, Germany (M. Apostolopoulou, M. Roden); German Center for Diabetes Research (DZD e.V.), Düsseldorf, Germany (M. Apostolopoulou, M. Roden); Dipartimento di Scienze Farmacologiche e Biomolecolari (DISFeB), Università degli Studi di Milano, Via Balzaretti, 9, 20133 Milano, Italy (A. Corsini); IRCCS Multimedica, Milano, Italy (A. Corsini); Department of Endocrinology and Diabetology, Medical Faculty, Heinrich Heine University, c/o Auf'm Hennekamp 65, 40225 Düsseldorf, Germany (M. Roden).

Correspondence to: Dr Michael Roden, Department of Endocrinology and Diabetology, Medical Faculty, University Hospital Düsseldorf and Institute for Clinical Diabetology, German Diabetes Center, Heinrich-Heine University, c/o Auf'm Hennekamp 65, 40225 Düsseldorf, Germany. Tel.: (49) 2113382 201; fax: (49) 2113382 690; e-mail: michael.roden@ddz. uni-duesseldorf.de

Received 30 January 2015; accepted 13 May 2015

\section{References}

1 Maron DJ, Fazio S, Linton MF. Current perspectives on statins. Circulation 2000;101:207-13.

2 Davignon J. Beneficial cardiovascular pleiotropic effects of statins. Circulation 2004;109:Iii39-43.

3 Taylor F, Huffman MD, Macedo AF, Moore TH, Burke M, Davey Smith $\mathrm{G}$ et al. Statins for the primary prevention of cardiovascular disease. Cochrane Database Syst Rev 2013;1:CD004816.

4 Abd TT, Jacobson TA. Statin-induced myopathy: a review and update. Expert Opin Drug Saf 2011;10:373-87.

5 Bruckert E, Hayem G, Dejager S, Yau C, Bégaud B. Mild to moderate muscular symptoms with high-dosage statin therapy in hyperlipidemic patients - the PRIMO study. Cardiovasc Drugs Ther 2005;19:403-14.

6 Needham M, Mastaglia FL. Statin myotoxicity: a review of genetic susceptibility factors. Neuromuscul Disord 2014;24:4-15.

7 Graham DJ, Staffa JA, Shatin D, Andrade SE, Schech SD, La Grenade $\mathrm{L}$ et al. Incidence of hospitalized rhabdomyolysis in patients treated with lipid-lowering drugs. JAMA 2004;292:2585-90.

8 Stroes ES, Thompson PD, Corsini A, Vladutiu GD, Raal FJ, Ray KK et al. Statin-associated muscle symptoms: impact on statin therapyEuropean Atherosclerosis Society consensus panel statement on assessment, aetiology and management. Eur Heart J 2015;36:1012-22. 
9 Marcoff L, Thompson PD. The role of coenzyme Q10 in statinassociated myopathy: a systematic review. J Am Coll Cardiol 2007;49:2231-7.

10 Golomb BA, Evans MA. Statin adverse effects: a review of the literature and evidence for a mitochondrial mechanism. Am J Cardiovasc Drugs 2008;8:373-418.

11 Bitzur R, Cohen H, Kamari Y, Harats D. Intolerance to statins: mechanisms and management. Diabetes Care 2013;36(Suppl 2):S325-30.

12 Baker SK. Molecular clues into the pathogenesis of statin-mediated muscle toxicity. Muscle Nerve 2005;31:572-80.

13 Mason RP, Walter MF, Jacob RF. Effects of HMG-CoA reductase inhibitors on endothelial function: role of microdomains and oxidative stress. Circulation 2004;109:Ii34-41.

14 Araki M, Maeda M, Motojima K. Hydrophobic statins induce autophagy and cell death in human rhabdomyosarcoma cells by depleting geranylgeranyl diphosphate. Eur J Pharmacol 2012;674:95103.

15 Vaklavas C, Chatzizisis YS, Ziakas A, Zamboulis C, Giannoglou GD. Molecular basis of statin-associated myopathy. Atherosclerosis 2009;202:18-28.

16 Siddals KW, Marshman E, Westwood M, Gibson JM. Abrogation of insulin-like growth factor-I (IGF-I) and insulin action by mevalonic acid depletion: synergy between protein prenylation and receptor glycosylation pathways. J Biol Chem 2004;279:38353-9.

17 J-i Hanai, Cao P, Tanksale P, Imamura S, Koshimizu E, Zhao J et al. The muscle-specific ubiquitin ligase atrogin-1/MAFbx mediates statin-induced muscle toxicity. J Clin Investig 2007;117:3940-51.

18 Cao P, Hanai J, Tanksale P, Imamura S, Sukhatme VP, Lecker SH. Statin-induced muscle damage and atrogin-1 induction is the result of a geranylgeranylation defect. FASEB J 2009;23:2844-54.

19 De Pinieux G, Chariot P, Ammi-Said M, Louarn F, Lejonc JL, Astier A et al. Lipid-lowering drugs and mitochondrial function: effects of HMG-CoA reductase inhibitors on serum ubiquinone and blood lactate/pyruvate ratio. Br J Clin Pharmacol 1996;42:333-7.

20 Laaksonen R, Ojala JP, Tikkanen MJ, Himberg JJ. Serum ubiquinone concentrations after short- and long-term treatment with HMG-CoA reductase inhibitors. Eur J Clin Pharmacol 1994;46:313-7.

21 Toyama K, Sugiyama S, Oka H, Iwasaki Y, Sumida H, Tanaka T et al. Rosuvastatin combined with regular exercise preserves coenzyme Q10 levels associated with a significant increase in highdensity lipoprotein cholesterol in patients with coronary artery disease. Atherosclerosis 2011;217:158-64.

22 Paiva H, Thelen KM, Van Coster R, Smet J, De Paepe B, Mattila KM et al. High-dose statins and skeletal muscle metabolism in humans: a randomized, controlled trial. Clin Pharmacol Ther 2005;78:60-8.

23 Larsen S, Stride N, Hey-Mogensen M, Hansen CN, Bang LE, Bundgaard $\mathrm{H}$ et al. Simvastatin effects on skeletal muscle: relation to decreased mitochondrial function and glucose intolerance. J Am Coll Cardiol 2013;61:44-53.

24 Schick BA, Laaksonen R, Frohlich JJ, Paiva H, Lehtimaki T, Humphries KH et al. Decreased skeletal muscle mitochondrial DNA in patients treated with high-dose simvastatin. Clin Pharmacol Ther 2007;81:650-3.

25 Miyake Y, Shouzu A, Nishikawa M, Yonemoto T, Shimizu H, Omoto $\mathrm{S}$ et al. Effect of treatment with 3-hydroxy-3-methylglutaryl coenzyme A reductase inhibitors on serum coenzyme Q10 in diabetic patients. Arzneimittelforschung 1999;49:324-9.

26 Folkers K, Langsjoen P, Willis R, Richardson P, Xia LJ, Ye CQ et al. Lovastatin decreases coenzyme Q levels in humans. Proc Natl Acad Sci USA 1990;87:8931-4.
27 Bargossi AM, Grossi G, Fiorella PL, Gaddi A, Di Giulio R, Battino M Exogenous CoQ10 supplementation prevents plasma ubiquinone reduction induced by HMG-CoA reductase inhibitors. Mol Aspects Med 1994;15(Suppl):s187-93.

28 Silver MA, Langsjoen PH, Szabo S, Patil H, Zelinger A. Effect of atorvastatin on left ventricular diastolic function and ability of coenzyme Q10 to reverse that dysfunction. Am J Cardiol 2004;94:1306-10.

29 Thibault A, Samid D, Tompkins AC, Figg WD, Cooper MR, Hohl RJ et al. Phase I study of lovastatin, an inhibitor of the mevalonate pathway, in patients with cancer. Clin Cancer Res 1996;2:483-91.

30 Kim WS, Kim MM, Choi HJ, Yoon SS, Lee MH, Park K et al. Phase II study of high-dose lovastatin in patients with advanced gastric adenocarcinoma. Invest New Drugs 2001;19:81-3.

31 Skarlovnik A, Janic M, Lunder M, Turk M, Sabovic M. Coenzyme Q10 supplementation decreases statin-related mild-to-moderate muscle symptoms: a randomized clinical study. Med Sci Monit 2014;20:2183-8.

32 Bogsrud MP, Langslet G, Ose L, Arnesen KE, Sm Stuen MC, Malt UF et al. No effect of combined coenzyme Q10 and selenium supplementation on atorvastatin-induced myopathy. Scand Cardiovasc J 2013;47:80-7.

33 Schaars CF, Stalenhoef AF. Effects of ubiquinone (coenzyme Q10) on myopathy in statin users. Curr Opin Lipidol 2008;19:553-7.

34 Taylor BA, Lorson L, White CM, Thompson PD. A randomized trial of coenzyme Q10 in patients with confirmed Statin Myopathy. Atherosclerosis 2014;238:329-35.

35 National Clinical Guideline Centre. Lipid Modification: Cardiovascular Risk Assessment and the Modification of Blood Lipids for the Primary and Secondary Prevention of Cardiovascular Disease. London: National Clinical Guideline Centre; 2014: 2014.

36 Sugiyama S. HMG CoA reductase inhibitor accelerates aging effect on diaphragm mitochondrial respiratory function in rats. Biochem Mol Biol Int 1998;46:923-31.

37 Hattori T, Saito K, Takemura M, Ito H, Ohta H, Wada H et al. Statininduced $\mathrm{Ca}(2+)$ release was increased in $\mathrm{B}$ lymphocytes in patients who showed elevated serum creatine kinase during statin treatment. J Atheroscler Thromb 2009;16:870-7.

38 Nakahara K, Yada T, Kuriyama M, Osame M. Cytosolic Ca2+ increase and cell damage in L6 rat myoblasts by HMG-CoA reductase inhibitors. Biochem Biophys Res Commun 1994;202:1579-85.

39 Sirvent P, Mercier J, Vassort G, Lacampagne A. Simvastatin triggers mitochondria-induced $\mathrm{Ca} 2+$ signaling alteration in skeletal muscle. Biochem Biophys Res Commun 2005;329:1067-75.

40 Pierno S, Camerino GM, Cippone V, Rolland JF, Desaphy JF, De Luca A et al. Statins and fenofibrate affect skeletal muscle chloride conductance in rats by differently impairing ClC- 1 channel regulation and expression. Br J Pharmacol 2009;156:1206-15.

41 Kwak HB, Thalacker-Mercer A, Anderson EJ, Lin CT, Kane DA, Lee NS et al. Simvastatin impairs ADP-stimulated respiration and increases mitochondrial oxidative stress in primary human skeletal myotubes. Free Radic Biol Med 2012;52:198-207.

42 Bouitbir J, Charles AL, Echaniz-Laguna A, Kindo M, Daussin F, Auwerx J et al. Opposite effects of statins on mitochondria of cardiac and skeletal muscles: a 'mitohormesis' mechanism involving reactive oxygen species and PGC-1. Eur Heart J 2012;33:1397-407.

43 Kaufmann P, Torok M, Zahno A, Waldhauser KM, Brecht K, Krahenbuhl S. Toxicity of statins on rat skeletal muscle mitochondria. Cell Mol Life Sci 2006;63:2415-25. 
44 Mullen PJ, Zahno A, Lindinger P, Maseneni S, Felser A, Krahenbuhl $\mathrm{S}$ et al. Susceptibility to simvastatin-induced toxicity is partly determined by mitochondrial respiration and phosphorylation state of Akt. Biochim Biophys Acta 2011;1813:2079-87.

45 Vaughan RA, Garcia-Smith R, Bisoffi M, Conn CA, Trujillo KA. Ubiquinol rescues simvastatin-suppression of mitochondrial content, function and metabolism: implications for statin-induced rhabdomyolysis. Eur J Pharmacol 2013;711:1-9.

46 Nakahara K, Kuriyama M, Sonoda Y, Yoshidome H, Nakagawa H, Fujiyama $\mathrm{J}$ et al. Myopathy induced by HMG-CoA reductase inhibitors in rabbits: a pathological, electrophysiological, and biochemical study. Toxicol Appl Pharmacol 1998;152:99-106.

47 Schaefer WH, Lawrence JW, Loughlin AF, Stoffregen DA, Mixson LA, Dean DC et al. Evaluation of ubiquinone concentration and mitochondrial function relative to cerivastatin-induced skeletal myopathy in rats. Toxicol Appl Pharmacol 2004;194:10-23.

48 Obayashi H, Nezu Y, Yokota H, Kiyosawa N, Mori K, Maeda N et al. Cerivastatin induces type-I fiber-, not type-II fiber-, predominant muscular toxicity in the young male F344 rats. J Toxicol Sci 2011;36:445-52.

49 Bouitbir J, Daussin F, Charles AL, Rasseneur L, Dufour S, Richard R et al. Mitochondria of trained skeletal muscle are protected from deleterious effects of statins. Muscle Nerve 2012;46:367-73.

50 Ranji P, Rauthan M, Pitot C, Pilon M. Loss of HMG-CoA reductase in C. elegans causes defects in protein prenylation and muscle mitochondria. PLoS ONE 2014;9:e100033.

51 Lamperti C, Naini AB, Lucchini V, Prelle A, Bresolin N, Moggio M et al. Muscle coenzyme Q10 level in statin-related myopathy. Arch Neurol 2005;62:1709-12.

52 Guis S, Figarella-Branger D, Mattei JP, Nicoli F, Le Fur Y, KozakRibbens $\mathrm{G}$ et al. In vivo and in vitro characterization of skeletal muscle metabolism in patients with statin-induced adverse effects. Arthritis Rheum 2006;55:551-7.

53 Traustadottir T, Stock AA, Harman SM. High-dose statin use does not impair aerobic capacity or skeletal muscle function in older adults. Age (Dordr) 2008;30:283-91.

$54 \mathrm{Wu}$ JS, Buettner C, Smithline H, Ngo LH, Greenman RL. Evaluation of skeletal muscle during calf exercise by 31-phosphorus magnetic resonance spectroscopy in patients on statin medications. Muscle Nerve 2011;43:76-81.

55 Mikus CR, Boyle LJ, Borengasser SJ, Oberlin DJ, Naples SP, Fletcher $\mathrm{J}$ et al. Simvastatin impairs exercise training adaptations. J Am Coll Cardiol 2013;62:709-14.

56 Stringer HA, Sohi GK, Maguire JA, Cote HC. Decreased skeletal muscle mitochondrial DNA in patients with statin-induced myopathy. J Neurol Sci 2013;325:142-7.

57 Parker BA, Capizzi JA, Grimaldi AS, Clarkson PM, Cole SM, Keadle $\mathrm{J}$ et al. Effect of statins on skeletal muscle function. Circulation 2013;127:96-103.

58 Phillips PS, Haas RH, Bannykh S, Hathaway S, Gray NL, Kimura BJ et al. Statin-associated myopathy with normal creatine kinase levels. Ann Intern Med 2002;137:581-5.

59 Gambelli S, Dotti MT, Malandrini A, Mondelli M, Stromillo ML, Gaudiano $C$ et al. Mitochondrial alterations in muscle biopsies of patients on statin therapy. J Submicrosc Cytol Pathol 2004;36:85-9.

60 Laaksonen R, Jokelainen K, Laakso J, Sahi T, Harkonen M, Tikkanen $\mathrm{MJ}$ et al. The effect of simvastatin treatment on natural antioxidants in low-density lipoproteins and high-energy phosphates and ubiquinone in skeletal muscle. Am J Cardiol 1996;77:851-4.

61 Szendroedi J, Phielix E, Roden M. The role of mitochondria in insulin resistance and type 2 diabetes mellitus. Nat Rev Endocrinol 2012;8:92-103.

62 Pasternak RC, Smith SC Jr, Bairey-Merz CN, Grundy SM, Cleeman JI, Lenfant C. ACC/AHA/NHLBI clinical advisory on the use and safety of statins. J Am Coll Cardiol 2002;40:567-72.

63 Voora D, Shah SH, Spasojevic I, Ali S, Reed CR, Salisbury BA et al. The SLCO1B1*5 genetic variant is associated with statin-induced side effects. J Am Coll Cardiol 2009;54:1609-16.

64 Berta E, Harangi M, Zsiros N, Nagy EV, Paragh G, Bodor M. Effect of thyroid hormone status and concomitant medication on statin induced adverse effects in hyperlipidemic patients. Pharmazie 2014;69:420-3.

65 Oh J, Ban MR, Miskie BA, Pollex RL, Hegele RA. Genetic determinants of statin intolerance. Lipids Health Dis 2007;6:7.

66 Canestaro WJ, Austin MA, Thummel KE. Genetic factors affecting statin concentrations and subsequent myopathy: a HuGENet systematic review. Genet Med 2014;16:810-9.

67 Frudakis TN, Thomas MJ, Ginjupalli SN, Handelin B, Gabriel R, Gomez HJ. CYP2D6*4 polymorphism is associated with statininduced muscle effects. Pharmacogenet Genomics 2007;17:695-707.

68 Vladutiu GD, Simmons Z, Isackson PJ, Tarnopolsky M, Peltier WL, Barboi AC et al. Genetic risk factors associated with lipid-lowering drug-induced myopathies. Muscle Nerve 2006;34:153-62.

69 Vladutiu GD, Isackson PJ, Kaufman K, Harley JB, Cobb B, Christopher-Stine L et al. Genetic risk for malignant hyperthermia in non-anesthesia-induced myopathies. Mol Genet Metab 2011;104: 167-73.

70 Feng QP, Wilke RA, Baye TM. Individualized risk for statin-induced myopathy: current knowledge, emerging challenges, and potential solutions. Pharmacogenomics 2012;13:579-94.

71 Thomas JE, Lee N, Thompson PD. Statins provoking MELAS syndrome. A case report. Eur Neurol 2007;57:232-5.

72 Szendroedi J, Schmid AI, Meyerspeer M, Cervin C, Kacerovsky M, Smekal Get al. Impaired mitochondrial function and insulin resistance of skeletal muscle in mitochondrial diabetes. Diabetes Care 2009;32:677-9.

73 Tay SK, Dimauro S, Pang AY, Lai PS, Yap HK. Myotoxicity of lipidlowering agents in a teenager with MELAS mutation. Pediatr Neurol 2008;39:426-8.

74 Page SR, Yee KC. Rhabdomyolysis in association with simvastatin and dosage increment in clarithromycin. Intern Med J 2014;44:690-3.

75 Morioka TY, Lee AJ, Bertisch S, Buettner C. Vitamin D status modifies the association between statin use and musculoskeletal pain: a population based study. Atherosclerosis 2014;238:77-82.

76 Nichols GA, Koro CE. Does statin therapy initiation increase the risk for myopathy? An observational study of 32,225 diabetic and nondiabetic patients. Clin Ther 2007;29:1761-70.

77 Link E, Parish S, Armitage J, Bowman L, Heath S, Matsuda F et al. SLCO1B1 variants and statin-induced myopathy - a genomewide study. N Engl J Med 2008;359:789-99.

78 Marzoa-Rivas R, Crespo-Leiro MG, Paniagua-Marin MJ, LlinaresGarcia D, Muniz-Garcia J, Aldama-Lopez G et al. Safety of statins when response is carefully monitored: a study of 336 heart recipients. Transpl Proc 2005;37:4071-3. 